\title{
Contralateral hemisphere as a lifeguard which is supported by melatonin for molecular and functional recovery after stroke
}

Ulkan Kilic ( $\square$ uckilic@yahoo.com )

University of Health Sciences Turkey https://orcid.org/0000-0002-6895-8560

Birsen Elibol

Bezmialem Vakif University https://orcid.org/0000-0002-9462-0862

Ahmet Burak Caglayan

Istanbul Medipol Universitesi

Mustafa Caglar Beker

Istanbul Medipol Universitesi

Merve Beker

Univesity of Health Sciences Turkey

Burcugul Altug-Tasa

Eskisehir Teknik Universitesi

Omer Uysal

Bezmialem Vakif Universitesi Tip Fakultesi

Bayram Yilmaz

Yeditepe Universitesi Tip Fakultesi

Ertugrul Kilic

Istanbul Medipol Universitesi

\section{Research}

Keywords:

Posted Date: August 11th, 2020

DOl: https://doi.org/10.21203/rs.3.rs-45391/v1

License: (c) (i) This work is licensed under a Creative Commons Attribution 4.0 International License.

Read Full License 


\section{Abstract}

Successful functional recovery from stroke is crucial in the rehabilitation of patients and mainly depends on several ischemia-induced processes, including cell survival and apoptosis. Melatonin is an interesting candidate for secondary stroke prevention due to its effect on signaling pathways. Therefore, we investigated the coordination of ipsilateral and contralateral hemispheres to evaluate delayed post-acute effect of melatonin on recovery of the cell survival and apoptosis after stroke. Melatonin was administered ( $4 \mathrm{mg} / \mathrm{kg} /$ day) intraperitoneally for 45 days, starting 3-day after 30-min of middle cerebral artery occlusion. The genes and proteins related to the cell survival and apoptosis were investigated by immunofluorescence, western blotting and RT-PCR techniques after behavioral experiments. Melatonin produced delayed neurological recovery by improving motor coordination, which was also reflected by enhanced neuronal survival and reduced apoptosis in the post-acute phase of stroke in both contralateral and ipsilateral hemispheres. The increase of NGF, Nrp1, c-jun; activation of AKT; and dephosphorylation of ERK and JNK at the 55th day showed that cell survival and apoptosis signaling molecules compete to contribute to the remodeling of brain. Furthermore, an increase in the CREB and Atf-1 expressions suggested the melatonin's strong reformative effect on neuronal regeneration. The contralateral hemisphere was more active at the latter stages of the molecular and functional regeneration which provides a further proof of principle about melatonin's action on the promotion of brain plasticity and recovery after stroke.

\section{Introduction}

Melatonin ( $\mathrm{N}$-acetyl-5-methoxytryptamine) is a powerful neuroprotectant due to its anti-apoptotic [1], antiinflammatory [2], antioxidative [3], and analgesic properties [4]. Therefore, previous investigations have shown that melatonin may be a beneficial molecule against neurodegenerative diseases $[5,6]$ and cognitive disorders $[7,8]$. Studies have also indicated that melatonin protects the brain against focal cerebral ischemia in rodents [9-13]. It is thought that the protective and regenerative effects of melatonin may be due to its antioxidant functions and strong activation of pro-survival signaling pathways $[14,15]$.

Melatonin has been widely known to reduce programmed cell death with its antioxidant properties [16, 17]. In addition, melatonin protects the survival and differentiation of cerebellar neurons [18]. The antiapoptotic effect of pharmacological melatonin treatments has also been shown in vivo, especially in our previous studies [14, 19-22]. Besides its prophylactic effects, we have determined that treatment with melatonin 24 hours after stroke shows acute neuroprotective effects. To make melatonin more suitable for clinical use, we have examined its cooperative interaction with memantine, which has found usage in Alzheimer's disease and epilepsy treatment and inhibits overexpression of NMDA receptor, and a thrombolytic recombinant tissue plasminogen activator (rt-PA) that has a role in brain ischemia pathophysiology [23]. In addition to these studies, we also noted that melatonin shows its neuroprotective effects through a mechanism independent of its membrane receptors because in the absence of MT1 and MT2 no unfavorable effect of melatonin was found on ischemic brain injury [24]. 
While melatonin's beneficial effects have been documented in many studies, no study has verified the restorative effects of delayed melatonin treatment to enhance the cellular survival signaling pathways to improve functional outcomes during the stroke recovery period. In one of our previous studies, we noted that melatonin enhanced neurogenesis with functional recovery, even when applied 1 day after stroke for 29 days [25]. In the present study, we examined how melatonin influences cell survival and apoptosis rather than neurogenesis when administered intraperitoneally starting later ( 3 days after 30 min of middle cerebral artery occlusion), for a longer exposure time ( 45 days) in the post-acute ischemic brain.

\section{Materials And Methods}

\section{Animal groups}

Two groups of male C57BL/ 6 mice $(21-25 \mathrm{~g})$ with a total number of 52 , that underwent 30 -min of leftsided middle cerebral artery occlusion (MCAO) only or MCAO plus melatonin were sacrificed at four different post-ischemic times $(3,14,30$, and 55 days) ( $n=6-10$ animals/group). No randomization was performed to allocate subjects in the study and no sample calculation was performed before the experiment.

All procedures were approved by the Animal Care and Use Committee of Yeditepe University (06/09/2011 - 206) and complied with the National Institutes of Health (NIH) Guide for the Care and Use of Laboratory Animals.

\section{Induction of ischemia}

The 30-min stroke model which causes apoptotic cell death in the striatum was achieved by left MCAO under anesthesia as described previously [25]. Focal ischemia was induced using an intraluminal filament technique by ligating the left common and external carotid arteries. After 30-min, the coated thread was withdrawn to initiate reperfusion and animals were placed into their home cages [26]. The cerebral blood flow was recorded by laser Doppler flow (LDF).

\section{Application of intraperitoneal melatonin}

To evaluate the regenerative/restorative effect of melatonin rather than its neuroprotective effect, melatonin treatment was started three days after surgery because this time is accepted that acute pathophysiological changes are completed $[25,27,28]$. At $72 \mathrm{~h}$ post-ischemia, mini-osmotic pumps (Alzet 2006, USA) filled with $10 \%$ ethanol (vehicle) or melatonin (4 mg/kg/day) [24] were implanted intraperitoneally for 45 days.

\section{Behavioral test}

The grip strength test consists of a spring balance coupled with a Newtonmeter (Medio-Line Spring Scale, metric, $300 \mathrm{~g}$, Pesola AG, Switzerland) that is attached to a triangular steel wire, which the animal instinctively grasps. When pulled by the tail, the animal exerts force on the steel wire [25]. Grip strength was evaluated at the right paretic forepaw; the left non-paretic forepaw being wrapped with adhesive 
tape. Grip strength was evaluated five times in each test, for which mean values were calculated. From these data, percentage values (post-ischemic versus pre-ischemic) were computed.

The rotarod consists of an accelerating drum, which allows the assessment of motor coordination skills. The time at which the animal falls off the drum is evaluated. Measurements were performed five times and their mean values were computed, from which percentage values (post-ischemic versus preischemic) were calculated by a blind observer.

\section{Conventional histochemical studies}

Ten days after behavioral experiments, animals were decapitated and their brain tissue were cut on a cryostat into $20 \mu \mathrm{m}$ coronal sections from the level of the bregma [26]. To observe ischemic hemisphere cresyl violet staining was performed. After that, three consecutive sections from each animal were fixed in $4 \%$ paraformaldehyde and pretreated for antigen retrieval with citrate buffer. After blocking with $10 \%$ normal goat serum brain sections were incubated overnight with monoclonal mouse anti-NeuN antibody (Chemicon, USA) that was detected with Cy3-conjugated secondary antibody (Jackson ImmunoResearch, UK). Sections counterstained with 4'-6-diamidino-2-phenylindole (DAPI) were evaluated under a fluorescence microscope (Olympus BX41, UK). Surviving neurons were analyzed in a blinded way by counting the numbers of cells/profiles in six regions of interest (ROIs) $\left(62500 \mu \mathrm{m}^{2}\right.$ each) per striatum. Then percentage of NeuN positive cells were analyzed by calculating the ratio of cells in ipsilesional striatum to contralesional one $[29,30]$.

For detection ofDNA fragmentation, TUNEL staining was performed to fixed coronal sections [31]. Briefly, after labeling with terminal deoxynucleotidyl transferase mix (Roche, Switzerland), sections were stained with streptavidin-FITC, counterstained with DAPI and evaluated by counting DNA fragmented cells in nine ROIs ( $62500 \mu \mathrm{m}^{2}$ each) in the whole ischemic striatum under a fluorescence microscope by a blind observer [29].

\section{Gene expression studies}

After trans-cardiac perfusion with PBS, the samples of the striatum and prefrontal cortex both ipsilateral and contralateral to the stroke were collected and homogenized to isolate total RNA with TRIzol and PureLink RNA mini kit (Thermo Fischer Scientific, USA) ( $n=6-10$ animals/group). After determination of the isolated RNA amount by Qubit fluorometry, complementary DNA was synthesized (Applied Biosystems, USA) and real time polymerase chain reaction (RT-PCR) was performed with the appropriate thermal cycles in a Fast RT-PCR system (Applied Biosystems, USA) for seven different genes that are usually studied in brain ischemia [32-34] together with two housekeeping genes, glyceraldehyde-3phosphate dehydrogenase (GAPDH) and 18S rRNA. The studied genes were neuropilin-1 (Nrp 1), cyclindependent kinase inhibitor 1A (Cdkn1a), nerve growth factor (NGF), insulin growth factor-1 (IGF1), jun proto-oncogene (c-jun), phosphatase and tensin homolog (PTEM), and caspase 3 (Casp3) as cell survival genes. Gene cards were analyzed using the threshold cycle $\left(\mathrm{C}_{T}\right)$ relative quantification method according to the mean values of triplicate analysis within each group. 


\section{Protein expression studies with western blot analysis}

Striatal samples were homogenized with lysis buffer (1 M Tris-HCl, $5 \mathrm{M} \mathrm{NaCl}$, Triton-X-100, 0.5 M EDTA, protease inhibitor cocktail (\#20-201, Millipore) and centrifuged at $4{ }^{\circ} \mathrm{C}$. The collected supernatants that were pooled ( $n=6-10$ animals/group) were used for sodium dodecylsulfate-polyacrylamide gel electrophoresis [27]. Equal amounts of protein which were determined with Qubit Fluorometer 2.0 (\#Q32866; Invitrogen) were diluted in sample buffer, boiled, and loaded onto 4-12\% Bis-Tris polyacrylamide gels (\#NP0321BOX; Invitrogen). Proteins were transferred onto PVDF membranes with gel transfer system (Thermo Fischer Scientific, USA). Membranes were incubated in blocking solution and immersed with primary antibodies: phospho-Akt (Cell Signaling Technology, USA), Akt (LifeSpan Bio, USA), phospho-p44/42 (ERK) (Cell Signaling Technology, USA), p44/42 (ERK) (Cell Signaling Technology, USA), phospho-SAPK/JNK (Cell Signaling Technology, USA), SAPK/JNK (Cell Signaling Technology, USA), CREB (Millipore, USA), p38 (Millipore, USA), and p53 (Cell Signaling Technology, USA) each diluted in 5\% milk powder in $0.1 \%$ Tween $20 / 0.1 \mathrm{M}$ Tris buffer. Then, membranes were incubated in peroxidase-coupled secondary antibodies they detected with the Fusion $\mathrm{FX}_{7}$ system (Vilber Lourmat, France). Protein loading was controlled with a monoclonal mouse antibody against $\beta$-actin (Cell Signaling Technology, USA) in the same membrane after using stripping buffer. Blots were performed at least three times. Protein levels were analyzed densitometrically using ImageJ (National Institute of Health, USA).

\section{Data analysis and statistics}

All values are given as mean \pm S.D. For gene expression studies, $\triangle$ Ct values are used for statistical analysis. In the behavioral tests, repeated measures of ANOVA were applied. One-way ANOVA followed by the Tukey HSD post-hoc tests or by the unpaired two-tailed t-test were used for statistical analysis of immunofluorescence data. Lastly, Western blot data was analyzed by 3-way ANOVA using day, group and the hemisphere of brain as independent variable (SPSS 18.0, Germany). $p \leq 0.05$ was accepted as statistically significant.

\section{Results}

To observe the induction of ischemia, LDF recordings were performed and a decrease of LDF during intraluminal MCA thread occlusion and an increase in the LDF value during reperfusion were noted (Fig. 1A). In addition, cresyl violet stained sections were used to observe the ischemic hemisphere (Fig. 1A). According to the repeated measure of ANOVA, there was a significant day effect in the motor coordination $(F=11.617, p<0.001)$ and grip strength test $(F=53.499, p<0.001)$. Significant reductions in motor force and coordination skills were noticed in animals subjected to 30-min of MCAO. At the third day of ischemia, there was a decline in the grip strength test in both groups compared to pre-ischemic values while there was no significant difference between-groups. In the following days, melatonin treatment ameliorated grip strength of animals producing a significant increase at day 45 compared to the control group $(p<0.05)$ (Fig. 1B). Motor coordination of animals receiving melatonin increased in the post- 
ischemic period reaching statistically significant values at day 45 compared to vehicle-treated ischemic animals' performance approaching to the baseline levels $(p<0.05)$ (Fig. 1C).

To assess how melatonin affects neuronal survival, immunohistochemistry against the neuronal marker NeuN was analyzed. Following 14 days after induction of ischemia, the percentage of surviving neurons in the ipsilateral hemisphere $(\mathrm{IH})$ to the contralateral hemisphere $(\mathrm{CH})$ continuously declined. After that period, a slow increase in neuronal survival was observed. Notably, this increase in neuronal survival was dramatically higher in mice receiving melatonin at day $55(p<0.05)$ (Fig. 2$)$. The number of TUNELpositive cells in the ischemic striatum, as revealed by TUNEL staining, was significantly reduced at the 14th day and at the 55th day in melatonin-treated animals compared with vehicle-treated controls according to the unpaired two-tailed t-test (Fig. 3).

The expression of Cdkn1a-p21, and IGF1 genes was significantly increased in the ipsilateral prefrontal cortex but significantly decreased in the contralateral striatum by melatonin treatment at the 3rd day of ischemia. In addition, an increase in the expression of IGF1 in the ipsilateral striatum and NGF in the contralateral striatum was observed that 55th day. At the 14 th day, melatonin administration significantly reduced the expression of Nrp1 and IGF1 in ipsilateral striatum but increased IGF7expression levels in the contralateral prefrontal cortex. The observed change in the expression of the Cdkn1a gene at the 3rd day was also observed at the 14th day of ischemia. Indeed, a higher expression level was observed for the PTEN gene in both the contralateral and ipsilateral striatum at the 14th day of ischemia. At the 30th day of ischemia, melatonin treatment significantly reduced the expression of $c$-jun in both the cortex and striatum of the $\mathrm{IH}$. In the $\mathrm{CH}$, only the expression of IGF1 in the striatum was noted upon melatonin consumption at the 30th day of ischemia. Interestingly, the expression of the genes related to cell survival (Nrp1, NGF, c-jun, PTEN, and Casp3) significantly increased in the contralateral striatum, while their expression except that of Casp3, significantly decreased in the contralateral prefrontal cortex with melatonin administration at the 55th day of ischemia. In addition, at the 55th day, the expression of $c$-jun and PTEN significantly decreased in the ipsilateral striatum (Fig. 4).

The concentrations of proteins related to cell survival (AKT/ERK/JNK pathway) were significantly altered with melatonin therapy (Fig. 5A). There was a day $(F=670.24, p \leq 0.001)$, treatment $(F=24.34, p \leq$ 0.001), and brain hemisphere ( $\mathrm{IH}$ vs $\mathrm{CH})(\mathrm{F}=14.26, p=0.001)$ effect in the phosphorylation of AKT. The post-hoc test showed that the ratio of phosphorylated AKT to total AKT in the $\mathrm{CH}$ was significantly downregulated at day $3(p \leq 0.001)$. However, at day 55 , melatonin treatment significantly increased the pAKT/AKT ratio in the $\mathrm{CH}$ compared to control animals $(p=0.044)$ (Fig. 5B). In addition, there was a day $(\mathrm{F}=47.47, p \leq 0.001)$, and brain hemisphere $(\mathrm{IH}$ vs $\mathrm{CH})(\mathrm{F}=185.47, p<0.001)$ effect in the phosphorylation of ERK-1. However, the treatment effect was insignificant $(F=0.30, p=0.590)$. ERK-1 phosphorylation was upregulated at day 30 and downregulated at day 3 in the $\mathrm{CH}$ upon melatonin administration (Fig. 5C). On the other hand, a significant day $(\mathrm{F}=52.91, p<0.001)$, brain region $(\mathrm{F}=$ 353.31, $p<0.001)$ and treatment effect $(F=60.49, p<0.001)$ were observed on the phosphorylation of ERK-2. In the $\mathrm{CH}$, a significant decrease in the ERK2 phosphorylation due to melatonin administration was observed at the 3rd and 30th days (Fig. 5D). In addition, JNK phosphorylation was also affected by 
recovery time $(\mathrm{F}=108.08, p<0.001$ for $\mathrm{JNK}-1$ and $\mathrm{F}=26.59, p<0.001$ for $\mathrm{JNK}-2)$ and melatonin administration ( $\mathrm{F}=5.67, p=0.023$ for $\mathrm{JNK}-1$ and $\mathrm{F}=6.09, p=0.019$ for $\mathrm{JNK}-2)$. While there was no region effect in the JNK-1 expression, the region effect on the JNK-2 expression was significant $(F=41.46, p<$ 0.001). The expression of phosphorylated JNK-1 was significantly higher upon melatonin administration both in the $\mathrm{IH}$ and $\mathrm{CH}$ at the 14th day compared to control subjects (Fig. 5E). In the $\mathrm{CH}$, the expression of phosphorylated JNK-1 was significantly decreased at both the 3rd and 55th days (Fig. 5E). Furthermore, the phosphorylation of JNK-2 was significantly upregulated at the 14th and 30th days in the $\mathrm{IH}$ and was significantly downregulated at the 3rd, 14th, and 55th days in the $\mathrm{CH}$ (Fig. 5F).

Melatonin treatment affected the cell cycle regulators to control cell proliferation and cellular transcription factors (Fig. 6A). Melatonin administration significantly reduced the expression of phosphorylated p38 at days 3, 14, and 30 in both $\mathrm{IH}$ and $\mathrm{CH}$ (Fig. 6B). Furthermore, in the $\mathrm{IH}, \mathrm{p} 53$ expression was reduced at the 3rd and 14th days upon melatonin treatment. At days 30 and 55, p53 significantly increased in the melatonin-administered mice. In the $\mathrm{CH}, \mathrm{p} 53$ expression was significantly lower at the 3rd day (Fig. 6C).

According to 3-way ANOVA, there was a significant day $(\mathrm{F}=54.13, p<0.001, \mathrm{~F}=63.01, p<0.001$, respectively), region $(\mathrm{F}=8.82, p=0.006, \mathrm{~F}=40.66, p<0.001$, respectively), and treatment $(\mathrm{F}=11.07, p=$ $0.002, \mathrm{~F}=73.81, p<0.001$, respectively) effects on the expression of CREB and Atf-1 proteins. These blots revealed that $C R E B$ protein was significantly decreased at the 3rd day and increased at the 30th and 55th days in the $\mathrm{IH}$. In the $\mathrm{CH}$, the concentration of CREB was significantly lower at days 3, 14 and 30 and significantly higher at the 55th day in melatonin-treated mice (Fig. 6D). Atf-1 expression in the melatonin group was significantly reduced at the 3rd day in the $\mathrm{CH}$ and significantly increased at the 30th and 55th days in the $\mathrm{IH}$ and at the 14th and 55th days in the $\mathrm{CH}$ (Fig. 6E).

\section{Discussion}

To promote recovery in stroke patients, it has been a major challenge to develop effective therapeutics for inhibiting apoptosis and increasing cell survival after the latent period of brain ischemia. Previous studies showed that melatonin promotes neurological recovery beyond the acute stroke phase, and it may open new perspectives for post-acute therapies [10,34]. Herein, we have shown that post-acute delivery of melatonin, initiated as late as $72 \mathrm{~h}$ after focal cerebral ischemia, promotes neurological recovery in mice submitted to transient intraluminal MCAO by mechanisms involving cell survival and apoptosis.

A continued loss of surviving neurons takes place in the ipsilesional striatum of vehicle-treated mice submitted to transient intraluminal MCAO, which was reduced by melatonin in our study. The amelioration of the number of lost neurons in the ischemic hemisphere $(\mathrm{IH})$ reached a noteworthy level at the 55th day of melatonin administration suggesting that melatonin protected the brain against delayed neuronal death at the post-ischemic period. Our observations are in line with previous studies [28, 35], which reported an increase in the ipsilesional striatum in ischemic mice that was antagonized by some 
neuroprotective molecules for stroke treatment, such as adult neural precursor cells and erythropoietin, in the latter stages of the post-ischemic period.

The effect of melatonin on surviving neurons during the post-ischemic period was also observed in the genes related to cell survival. The increase in expression of NGF mRNA by melatonin at the 3rd and 55th days in the contralateral striatum may suggest the neuroprotective activity of melatonin by induction of NGF in both acute and post-acute stroke recovery in the IH after validation with protein levels. NGF has a role in stroke recovery due to its reducing effect on the occurrence of delayed neuronal death by regeneration of dendrites of affected neurons $[36,37]$ or induction of anti-apoptotic Bcl-2 protein expression and inhibition of pro-apoptotic Bax protein expression [38]. In a previous study, it was found that CREB protein, a cell survival promoter, is involved in the neuroprotective mechanisms of NGF during brain ischemia [39]. Parallel to the gene expression level of NGF increase at the latter stages of ischemia (day 55), CREB/Atf-1 expression increased in both the contralateral hemisphere $(\mathrm{CH})$ and $\mathrm{IH}$ by melatonin. The phosphorylation of CREB activates the immediate early genes for the regeneration processes. For that reason, the increase in the expression of CREB/Atf-1 during the post-acute period of stroke recovery proved melatonin's strong reformative effect on neuronal regeneration through the activation of the $\mathrm{PI3K} /$ Akt pathway to phosphorylate CREB [40]. Concurrently, we observed that melatonin increased Akt activation on the 55th day in the $\mathrm{CH}$ as observed by other investigators in the acute phase of stroke recovery $[22,41]$. Like the Akt pathway, the ERK-1/2 pathway has been implicated in the neuroprotective effects of melatonin as observed in other growth factors [11, 42]. ERK-1/2 acts as a transcriptional regulator activating downstream targets acting as cell death executioners in injured neurons [43] whereas Akt stabilizes mitochondrial function by phosphorylating Bad which then releases $\mathrm{Bcl}-\mathrm{XL}$ inside mitochondria for cell survival [44]. In addition, the SAPK/JNK1-2 pathway regulates cell survival, apoptosis and proliferation. According to our results, suppression of JNK and activation of AKT points the studies in the post-ischemic brain which showed that the level of activated ERK1/2 and JNKs is reported to rapidly increase $[45,46]$, and inhibition of ERK $1 / 2$ or JNKs suppresses neuronal injury after transient or permanent MCAO in the rat $[47,48]$. Therefore, melatonin provides a neuroprotective effect against the detrimental role of ERK $1 / 2$ and JNK1/2 signaling by suppressing them during post-acute ischemic periods. In addition, the phosphatase PTEN, a tumor suppressor gene, controls the phosphorylation and activation of the survival kinases Akt and ERK1/2 by deactivating these pathways via downstream effectors $[49,50]$. The decrease in the PTEN mRNA in the ipsilateral striatum at the 55th day by melatonin may suggest nerve regeneration as noted previously [51, 52]. Furthermore, reports have shown several molecules that inhibit the activation of p38/MAPK to improve the outcome of ischemic brain injury by downregulating apoptosis signaling $[24,53,54]$. Herein, the expression of p38 decreased with melatonin at the first 30 post-ischemic days in both hemispheres, suggesting the inactivation of proapoptotic transcription factors and immediate early genes mediating apoptosis $[24,55,56]$. Another growth factor IGF1, whose expression is beneficial for stroke recovery [57], increased in the IH at the acute phase of stroke and in the $\mathrm{CH}$ at the latter stages of stroke upon melatonin administration. Induction of growth factor expression and neurogenesis by melatonin might be a positive adaptation for efficient repair and plasticity in the event of an ischemic insult. 
Short ischemic episodes, as induced by MCAO of less than one hour may cause disseminated neuronal injury via activation of apoptotic programs [27]. A delayed neuroprotective effect of melatonin was also observed in the form of inhibition of apoptotic cell injury, evidenced by the level of DNA fragmentation at the 14th and 55th days. In addition, the expression of Nrp1 gene, encoding a receptor for a chemorepulsive axon guidance factor (Sema3A) was significantly altered by melatonin. The Nrp1/Sema3A complex repels regenerating axons from entering the damaged territory and ultimately causing neuronal death during brain reperfusion following ischemia $[58,59]$. The decrease in the expression of the Nrp1 gene in the $\mathrm{IH}$ at the 14th day with melatonin may be a neuroprotective strategy to block the Nrp1/Sema3A interaction, decreasing the severity of neuronal death and enhancing neuronal survival/regeneration in ischemic brains. However, we observed a dramatic increase in the expression of $N r p 1$ in the contralateral striatum at the 55th day with melatonin. As we measured a decrease in apoptotic death by TUNEL staining during that period, these findings suggest that the increase in Nrp1 mRNA expression in the contralateral striatum is insufficient to induce neuronal death possibly because of untranslated mRNA molecules. However, a previous study showed that an alternative neuropilin ligand VEGF164, which competes Sema3A, promotes the survival of migrating neurons by coactivating the ERK and AKT signaling pathways through Nrp1 [60]. Further experiments are necessary to validate these results.

The Cdkn1a gene encodes the p21 protein which regulates cell cycle progression at $\mathrm{G} 1$ by binding and inhibiting the activity of Cdk2 [61]. The increased mRNA expression of Cdkn1a in the ipsilateral cortex and decreased expression in the contralateral striatum by melatonin suggested its strength in the regeneration of damaged tissue at the latter stages of recovery. The expression of p21 is tightly controlled by the tumor suppressor protein p53 [62] which plays a role in cell cycle arrest to induce apoptosis when DNA damage occurs. Melatonin decreased the expression of p53 in the first 14 days in the $\mathrm{IH}$ to compensate for rapid cell death in that period. We also investigated the expression of the $c-j u n$ gene which is activated through double phosphorylation by the JNK pathway. In the IH, the expression of $c-j u n$ mRNA decreased at the 30th and 55th days, which may suggest an increase in apoptosis at the latter stages because the decrease in c-jun expression can be related to the increase in p53 expression and those cells exhibit cell cycle defects. One of the functions of cell cycle arrest proteins is activating DNA repair proteins when DNA has sustained damage. Therefore, the increased p53 protein concentration in the latter stages of post-ischemia suggests melatonin's restorative effect on the damaged neurons. Moreover, the cleavage of p21 protein by caspases leads to abolishment of its interaction with proliferation cell nuclear antigen, resulting in interference with DNA repair and execution of apoptosis following caspase activation $[63,64]$. The expression of the Casp3 gene was increased by melatonin, but the expression of this gene decreased at the 14th day in the $\mathrm{IH}$ upon melatonin administration as seen in previous studies [10,31, 65]. Taguchi et al. [66] proposed that secondary neurodegeneration in the vicinity of the lesion may be relevant for stroke recovery. Therefore, the increase in apoptosis at the 55th day without DNA fragmentation may be necessary for reorganization of the regenerating neurons in the $\mathrm{IH}$.

In summary, we observed that delayed-melatonin administration has a role in the reorganization of the brain by increasing cell survival and inhibiting apoptosis both near and far from the stroke lesion as an 
acute therapy, while the mechanisms of cell survival and apoptosis compete with each other in the postacute therapy to effect functional recovery in the post-ischemic period. In particular, the contralateral hemisphere is more active at the latter stages of the regeneration period in terms of molecular and functional recovery (Fig. 7).

\section{Declarations}

\section{Declarations}

\section{Consent for publication}

Not applicable

\section{Ethics Approval}

All procedures were approved by the Animal Care and Use Committee of Yeditepe University (06/09/2011 - 206)

\section{Conflict of interest}

The authors of this article declare that they do not have any conflict of interest.

\section{Availability of data and materials}

Data sharing not applicable to this article as no datasets were generated or analysed during the current study

\section{Author contributions}

UK and EK designed all the experiments and $A B C$ and $M C B$ carried out experimental cerebral ischemia model. BE and MB performed western-blot and histological analysis. BAT performed quantitative RT-PCR analysis., BE and OU executed data analysis and performed statistical analysis. BY contributed to the work by technical and analytical support. UK, and BE participated in preparation of the manuscript. All authors read and approved the final manuscript.

\section{Acknowledgment}

This work was financially supported by the grant from the Turkish Scientific and Technical Council (TUBITAK, Grant number:111S418).

\section{References}


1. Hung MW, Tipoe GL, Poon AM, Reiter RJ, Fung ML. Protective effect of melatonin against hippocampal injury of rats with intermittent hypoxia. J Pineal Res. 2008;44(2):214-21.

2. Mauriz JL, Collado PS, Veneroso C, Reiter RJ, Gonzalez-Gallego J. A review of the molecular aspects of melatonin's anti-inflammatory actions: recent insights and new perspectives. J Pineal Res. 2013;54(1):1-14.

3. Garcia JJ, Lopez-Pingarron L, Almeida-Souza P, Tres A, Escudero P, Garcia-Gil FA, et al. Protective effects of melatonin in reducing oxidative stress and in preserving the fluidity of biological membranes: a review. J Pineal Res. 2014;56(3):225-37.

4. Gitto E, Aversa S, Salpietro CD, Barberi I, Arrigo T, Trimarchi G, et al. Pain in neonatal intensive care: role of melatonin as an analgesic antioxidant. J Pineal Res. 2012;52(3):291-5.

5. Mayo JC, Sainz RM, Tan DX, Antolin I, Rodriguez C, Reiter RJ. Melatonin and Parkinson's disease. Endocrine. 2005;27(2):169-78.

6. Rosales-Corral SA, Acuna-Castroviejo D, Coto-Montes A, Boga JA, Manchester LC, Fuentes-Broto L, et al. Alzheimer's disease: pathological mechanisms and the beneficial role of melatonin. J Pineal Res. 2012;52(2):167-202.

7. Cazzola R, Rondanelli M, Faliva M, Cestaro B. Effects of DHA-phospholipids, melatonin and tryptophan supplementation on erythrocyte membrane physico-chemical properties in elderly patients suffering from mild cognitive impairment. Exp Gerontol. 2012;47(12):974-8.

8. He P, Ouyang X, Zhou S, Yin W, Tang C, Laudon M, et al. A novel melatonin agonist Neu-P11 facilitates memory performance and improves cognitive impairment in a rat model of Alzheimer' disease. Horm Behav. 2013;64(1):1-7.

9. Kilic E, Ozdemir YG, Bolay H, Kelestimur H, Dalkara T. Pinealectomy aggravates and melatonin administration attenuates brain damage in focal ischemia. J Cereb Blood Flow Metab. 1999;19(5):511-6.

10. Kilic E, Kilic U, Yulug B, Hermann DM, Reiter RJ. Melatonin reduces disseminate neuronal death after mild focal ischemia in mice via inhibition of caspase- 3 and is suitable as an add-on treatment to tissue-plasminogen activator. J Pineal Res. 2004;36(3):171-6.

11. Kilic U, Kilic E, Reiter RJ, Bassetti CL, Hermann DM. Signal transduction pathways involved in melatonin-induced neuroprotection after focal cerebral ischemia in mice. J Pineal Res. 2005;38(1):67-71.

12. Pei Z, Fung PC, Cheung RT. Melatonin reduces nitric oxide level during ischemia but not blood-brain barrier breakdown during reperfusion in a rat middle cerebral artery occlusion stroke model. J Pineal Res. 2003;34(2):110-8.

13. Tai SH, Chen HY, Lee EJ, Chen TY, Lin HW, Hung YC, et al. Melatonin inhibits post-ischemic matrix metalloproteinase-9 (MMP-9) activation via dual modulation of plasminogen/plasmin system and endogenous MMP inhibitor in mice subjected to transient focal cerebral ischemia. J Pineal Res. 2010;49(4):332-41. 
14. Reiter RJ, Tan DX, Leon J, Kilic U, Kilic E. When melatonin gets on your nerves: Its beneficial actions in experimental models of stroke. Exp Biol Med. 2005;230(2):104-17.

15. Alonso-Alconada D, Alvarez A, Arteaga O, Martínez-lbargüen A, Hilario E. Neuroprotective effect of melatonin: a novel therapy against perinatal hypoxia-ischemia. Int J Mol Sci. 2013;14(5):9379-95.

16. Mayo JC, Sainz RM, Uria H, Antolin I, Esteban MM, Rodriguez C. Melatonin prevents apoptosis induced by 6-hydroxydopamine in neuronal cells: implications for Parkinson's disease. J Pineal Res. 1998;24(3):179-92.

17. Koc S, Cayli S, Aksakal C, Ocakli S, Soyalic H, Somuk BT, et al. Protective effects of melatonin and selenium against apoptosis of olfactory sensory neurons: A rat model study. Am J Rhinol Allergy. 2016;30(3):62-6.

18. Persengiev SP. The neuroprotective and antiapoptotic effects of melatonin in cerebellar neurons involve glucocorticoid receptor and p130 signal pathways. J Steroid Biochem Mol Biol. 2001;77(23):151-8.

19. Reiter RJ, Tan DX, Manchester LC, Lopez-Burillo S, Sainz RM, Mayo JC. Melatonin: detoxification of oxygen and nitrogen-based toxic reactants. Adv Exp Med Biol. 2003;527:539-48.

20. Andrabi SA, Sayeed I, Siemen D, Wolf G, Horn TFW. Direct inhibition of the mitochondrial permeability transition pore: a possible mechanism responsible for anti-apoptotic effects of melatonin. FASEB J. 2004;18(7):869-71.

21. Pei Z, Cheung RT. Pretreatment with melatonin exerts anti-inflammatory effects against ischemia/reperfusion injury in a rat middle cerebral artery occlusion stroke model. J Pineal Res. 2004;37(2):85-91.

22. Beker MC, Caglayan AB, Kelestemur T, Caglayan B, Yalcin E, Yulug B, et al. Effects of normobaric oxygen and melatonin on reperfusion injury: role of cerebral microcirculation. Oncotarget. 2015;6(31):30604-14.

23. Kilic U, Yilmaz B, Reiter RJ, Yuksel A, Kilic E. Effects of memantine and melatonin on signal transduction pathways vascular leakage and brain injury after focal cerebral ischemia in mice. Neuroscience. 2013;237:268-76.

24. Kilic U, Yilmaz B, Ugur M, Yuksel A, Reiter RJ, Hermann DM, et al. Evidence that membrane-bound G protein-coupled melatonin receptors MT1 and MT2 are not involved in the neuroprotective effects of melatonin in focal cerebral ischemia. J Pineal Res. 2012;52(2):228-35.

25. Kilic E, Kilic U, Bacigaluppi M, Guo Z, Abdallah NB, Wolfer DP, et al. Delayed melatonin administration promotes neuronal survival, neurogenesis and motor recovery, and attenuates hyperactivity and anxiety after mild focal cerebral ischemia in mice. J Pineal Res. 2008;45(2):142-8.

26. Kilic E, ElAli A, Kilic U, Guo Z, Ugur M, Uslu U, et al. Role of Nogo-A in neuronal survival in the reperfused ischemic brain. J Cereb Blood Flow Metab. 2010;30(5):969-84.

27. Hermann DM, Kilic E, Hata R, Hossmann KA, Mies G. Relationship between metabolic dysfunctions, gene responses and delayed cell death after mild focal cerebral ischemia in mice. Neuroscience. 2001;104(4):947-55. 
28. Reitmeir R, Kilic E, Kilic U, Bacigaluppi M, ElAli A, Salani G, et al. Post-acute delivery of erythropoietin induces stroke recovery by promoting perilesional tissue remodelling and contralesional pyramidal tract plasticity. Brain. 2011;134(Pt 1):84-99.

29. Kilic E, Kilic U, Soliz J, Bassetti CL, Gassmann M, Hermann DM. Brain-derived erythropoietin protects from focal cerebral ischemia by dual activation of ERK-1/-2 and Akt pathways. FASEB J. 2005;19(14):2026-8.

30. Kilic E, Kilic U, Wang Y, Bassetti CL, Marti HH, Hermann DM. The phosphatidylinositol-3 kinase/Akt pathway mediates VEGF's neuroprotective activity and induces blood brain barrier permeability after focal cerebral ischemia. FASEB J. 2006;20(8):1185-7.

31. Kilic E, Kilic U, Reiter RJ, Bassetti CL, Hermann DM. Tissue-plasminogen activator-induced ischemic brain injury is reversed by melatonin: role of iNOS and Akt. J Pineal Res. 2005;39(2):151-5.

32. Oliva AA Jr. Kang Y, Sanchez-Molano J, Furones C, Atkins CM. STAT3 signaling after traumatic brain injury. J Neurochem. 2012;120(5):710-20.

33. Zhou J, Du T, Li BM. Crosstalk between MAPK/ERK and PI3K/AKT signal pathways during brain ischemia/reperfusion. Asn Neuro. 2015;7(5):1759091415602463.

34. Reiter RJ. Oxidative damage in the central nervous system: protection by melatonin. Prog Neurobiol. 1998;56(3):359-84.

35. Bacigaluppi M, Pluchino S, Peruzzotti-Jametti L, Kilic E, Kilic U, Salani G, et al. Delayed postischaemic neuroprotection following systemic neural stem cell transplantation involves multiple mechanisms. Brain. 2009;132(Pt 8):2239-51.

36. Mattson MP, Cheng B. Growth factors protect neurons against excitotoxic/ischemic damage by stabilizing calcium homeostasis. Stroke. 1993;24(12 Suppl):I136-40; discussion I144-5..

37. Tanaka K, Tsukahara T, Kaku Y, Hashimoto N, Yonekawa Y, Ogata N, et al. Effect of nerve growth factor on delayed neuronal death and microtubule-associated protein 2 after transient cerebral ischaemia in the rat. J Clin Neurosci. 1994;1(2):125-30.

38. Tan YX, Wang DF, Li XM, Liu XM. Effects of nerve growth factor pretreatment on apoptosis of neurons and expression of Bcl-2, Bax protein in brain tissue following cerebral ischemia/reperfusion injury in gerbils. Zhongguo Wei Zhong Bing Ji Jiu Yi Xue. 2007;19(6):358-60.

39. Zhang ZH, Xi GM, Li WC, Ling HY, Qu P, Fang XB. Cyclic-AMP response element binding protein and tau are involved in the neuroprotective mechanisms of nerve growth factor during focal cerebral ischemia/reperfusion in rats. J Clin Neurosci. 2010;17(3):353-6.

40. Kong PJ, Byun JS, Lim SY, Lee JJ, Hong SJ, Kwon KJ, et al. Melatonin induces akt phosphorylation through melatonin receptor- and PI3K-dependent pathways in primary astrocytes. Korean $\mathrm{J}$ Physiol Pharmacol. 2008;12(2):37-41.

41. Ali T, Kim MO. Melatonin ameliorates amyloid beta-induced memory deficits, tau hyperphosphorylation and neurodegeneration via PI3/Akt/GSk3beta pathway in the mouse hippocampus. J Pineal Res. 2005;59(1):47-59. 
42. Han $\mathrm{BH}$, Holtzman DM. BDNF protects the neonatal brain from hypoxic-ischemic injury in vivo via the ERK pathway. J Neurosci. 2000;20(15):5775-81.

43. Irving EA, Bamford M. Role of mitogen- and stress-activated kinases in ischemic injury. J Cereb Blood Flow Metab. 2002;22(5):631-47.

44. Kilic E, Hermann DM, Kugler S, Kilic U, Holzmuller H, Schmeer C, et al. Adenovirus-mediated Bcl-X(L) expression using a neuron-specific synapsin-1 promoter protects against disseminated neuronal injury and brain infarction following focal cerebral ischemia in mice. Neurobiol Dis. 2002;11(2):27584.

45. Farrokhnia N, Roos MW, Terent A, Lennmyr F. Differential early mitogen-activated protein kinase activation in hyperglycemic ischemic brain injury in the rat. Eur J Clin Invest. 2005;35(7):457-63.

46. Shackelford DA, Yeh RY. Modulation of ERK and JNK activity by transient forebrain ischemia in rats. J Neurosci Res. 2006;83(3):476-88.

47. Alessandrini A, Namura S, Moskowitz MA, Bonventre JV. MEK1 protein kinase inhibition protects against damage resulting from focal cerebral ischemia. Proc Natl Acad Sci USA. 1999;96(22):12866-9.

48. Borsello T, Clarke PG, Hirt L, Vercelli A, Repici M, Schorderet DF, et al. A peptide inhibitor of c-Jun Nterminal kinase protects against excitotoxicity and cerebral ischemia. Nat Med. 2003;9(9):1180-6.

49. Gu J, Tamura M, Yamada KM. Tumor suppressor PTEN inhibits integrin- and growth factor-mediated mitogen-activated protein (MAP) kinase signaling pathways. J Cell Biol. 1998;143(5):1375-83.

50. Ning K, Pei L, Liao M, Liu B, Zhang Y, Jiang W, et al. Dual neuroprotective signaling mediated by downregulating two distinct phosphatase activities of PTEN. J Neurosci. 2004;24(16):4052-60.

51. Liu K, Lu Y, Lee JK, Samara R, Willenberg R, Sears-Kraxberger I, et al. PTEN deletion enhances the regenerative ability of adult corticospinal neurons. Nat Neurosci. 2010;13(9):1075-81.

52. Yu L, Liang H, Lu Z, Zhao G, Zhai M, Yang Y, et al. Membrane receptor-dependent Notch1/Hes1 activation by melatonin protects against myocardial ischemia-reperfusion injury: in vivo and in vitro studies. J Pineal Res. 2015;59(4):420-33.

53. Piao CS, Kim JB, Han PL, Lee JK. Administration of the p38 MAPK inhibitor SB203580 affords brain protection with a wide therapeutic window against focal ischemic insult. J Neurosci Res. 2003;73(4):537-44.

54. Nito C, Kamada H, Endo H, Niizuma K, Myer DJ, Chan PH. Role of the p38 mitogen-activated protein kinase/cytosolic phospholipase A2 signaling pathway in blood-brain barrier disruption after focal cerebral ischemia and reperfusion. J Cereb Blood Flow Metab. 2008;28(10):1686-96.

55. Lipton SA. Failures and successes of NMDA receptor antagonists: molecular basis for the use of open-channel blockers like memantine in the treatment of acute and chronic neurologic insults. NeuroRx. 2004;1(1):101-10.

56. Martel MA, Soriano FX, Baxter P, Rickman C, Duncan R, Wyllie DJ, et al. Inhibiting pro-death NMDA receptor signaling dependent on the NR2 PDZ ligand may not affect synaptic function or synaptic NMDA receptor signaling to gene expression. Channels. 2009;3(1):12-5. 
57. Bake S, Okoreeh AK, Alaniz RC, Sohrabji F. Insulin-like growth factor (IGF)-I modulates endothelial blood-brain barrier function in ischemic middle-aged female rats. Endocrinol. 2016;157(1):61-9.

58. Fujita H, Zhang B, Sato K, Tanaka J, Sakanaka M. Expressions of neuropilin-1, neuropilin-2 and semaphorin 3A mRNA in the rat brain after middle cerebral artery occlusion. Brain Res. 2001;914(12):1-14.

59. De Winter F, Holtmaat AJ, Verhaagen J. Neuropilin and class 3 semaphorins in nervous system regeneration. Adv Exp Med Biol. 2002;515:115-39.

60. Cariboni A, Davidson K, Dozio E, Memi F, Schwarz Q, Stossi F, et al. VEGF signalling controls GnRH neuron survival via NRP1 independently of KDR and blood vessels. Development. 2011;138(17):3723-33.

61. Gartel AL, Radhakrishnan SK. Lost in transcription: p21 repression, mechanisms, and consequences. Cancer Res. 2005;65(10):3980-5.

62. el-Deiry WS, Tokino T, Velculescu VE, Levy DB, Parsons R, Trent JM, et al. WAF1, a potential mediator of p53 tumor suppression. Cell. 1993;75(4):817-25.

63. Gervais JL, Seth P, Zhang H. Cleavage of CDK inhibitor p21(Cip1/Waf1) by caspases is an early event during DNA damage-induced apoptosis. J Biol Chem. 1998;273(30):19207-12.

64. Rodriguez R, Meuth M. Chk1 and p21 cooperate to prevent apoptosis during DNA replication fork stress. Mol Biol Cell. 2006;17(1):402-12.

65. Koh PO. Melatonin attenuates the cerebral ischemic injury via the MEK/ERK/p90RSK/Bad signaling cascade. J Vet Med Sci. 2008;70(11):1219-23.

66. Taguchi A, Wen Z, Myojin K, Yoshihara T, Nakagomi T, Nakayama D, et al. Granulocyte colonystimulating factor has a negative effect on stroke outcome in a murine model. Eur $\mathrm{J}$ Neurosci. 2007;26(1):126-33.

\section{Figures}




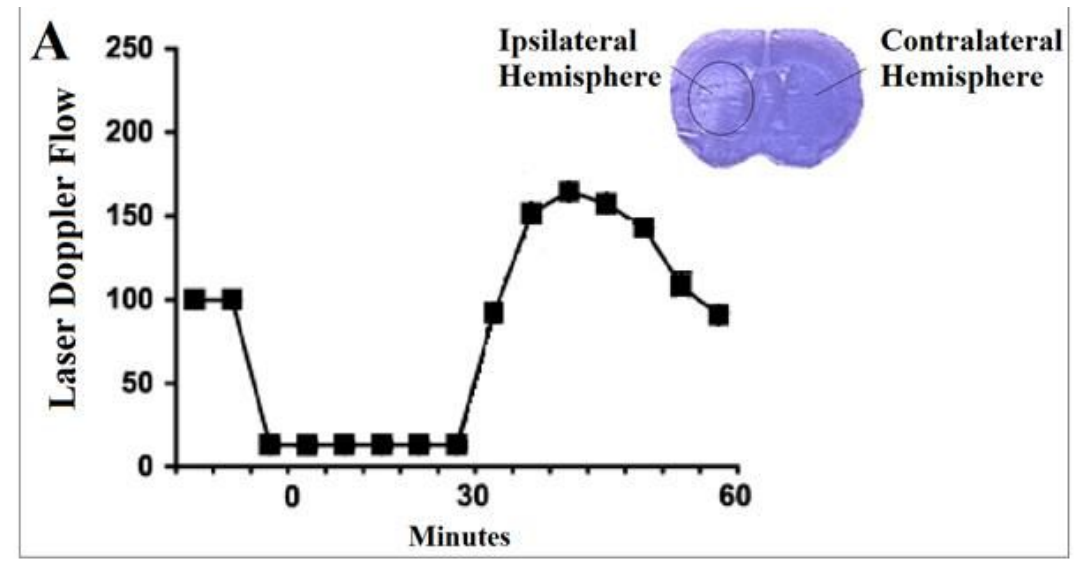

B

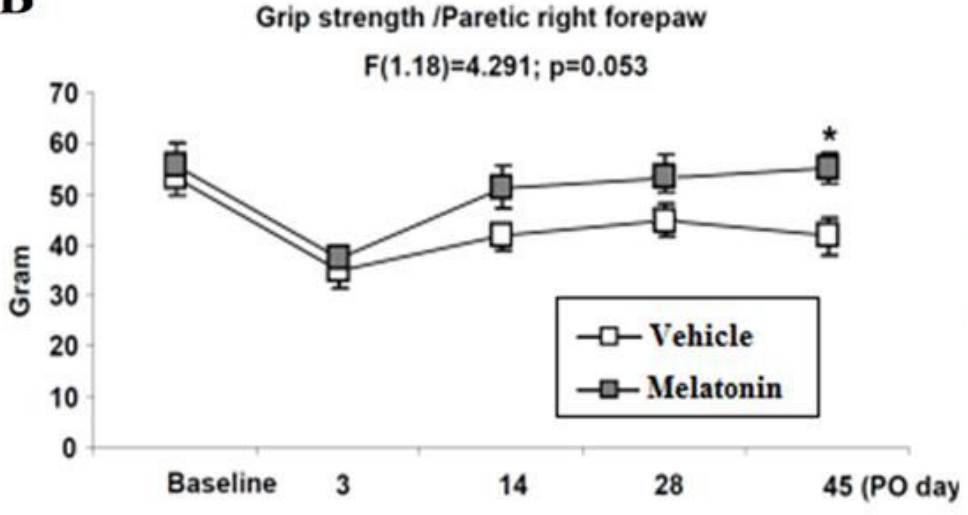

C

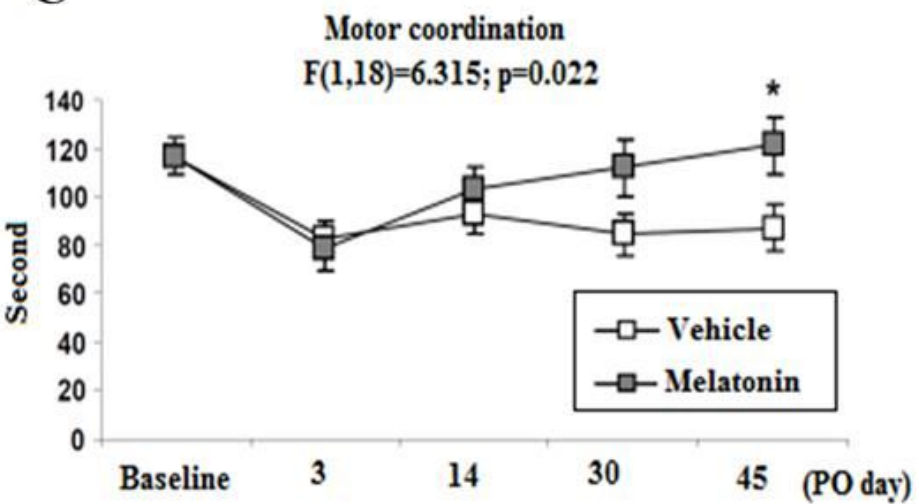

Figure 1

A) A representative laser Doppler flow (LDF) recordings during and after 30 min of intraluminal middle cerebral artery (MCA) occlusion and a representative cresyl violet stained section (at the 3rd day) showing ipsilateral and contralateral hemispheres in a mice. B) Delivery of melatonin from day 3 to day 45 of postischemia at $4 \mathrm{mg} / \mathrm{kg} /$ day promotes post-ischemic neurological recovery obtained from coordination skills evaluated by RotaRod tests. Data are mean values \pm S.D. ${ }^{*} p<0.05$ compared with vehicle-treated ischemic mice. $\mathrm{n}=6$ for vehicle group, $\mathrm{n}=7$ for melatonin group. $\mathrm{PO}=$ Post-Operation. 


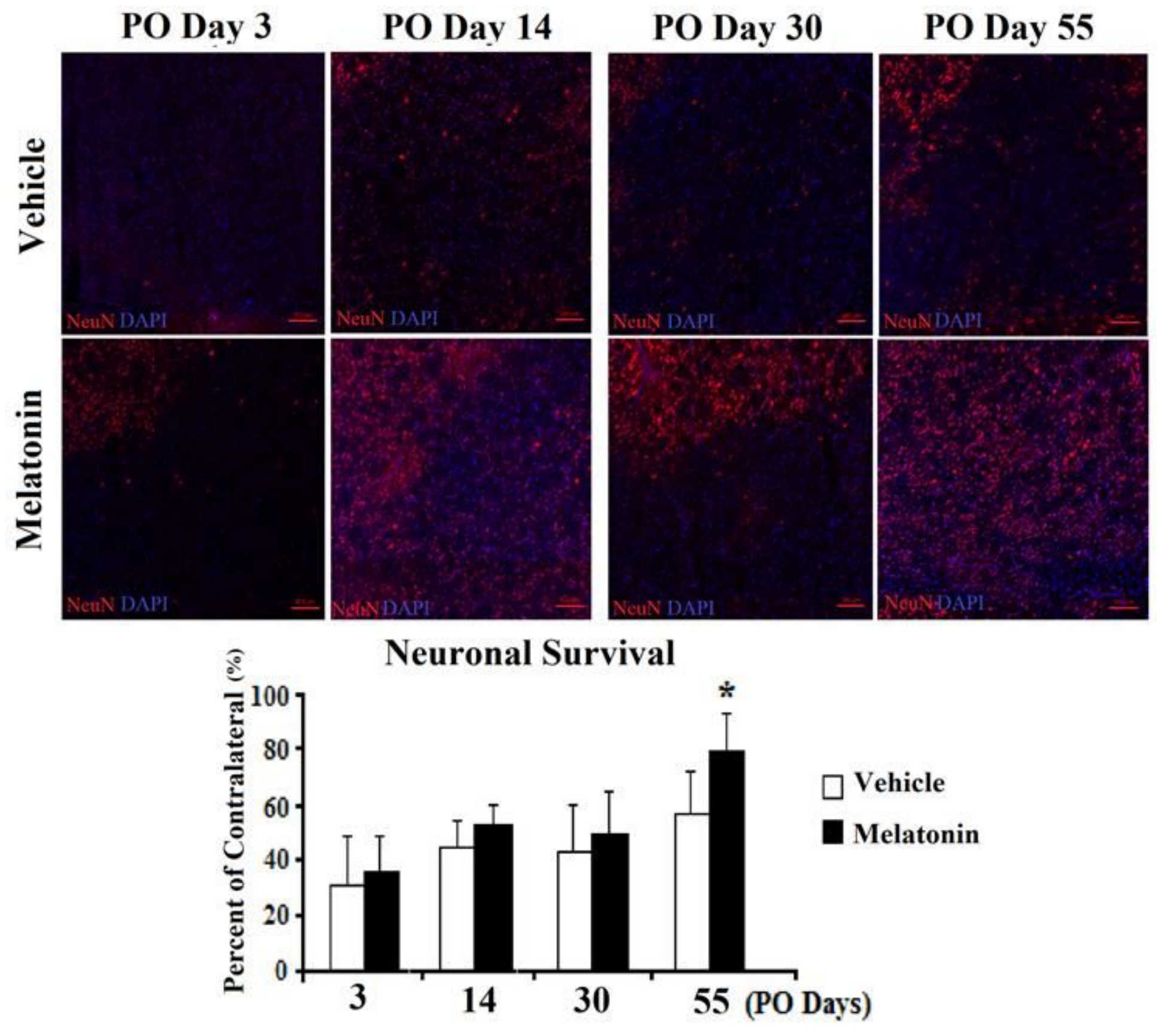

Figure 2

Delivery of melatonin increases post-ischemic neuronal survival which was obtained by immunofluorescence of NeuN (red) positive cells (DAPI (blue) for nuclear staining in ischemic mice treated with vehicle or melatonin ( $4 \mathrm{mg} / \mathrm{kg} / \mathrm{day})$ starting at 3-day post-ischemia. Data are mean values \pm SD. ${ }^{*} \mathrm{p}<0.05$ compared with vehicle-treated ischemic mice. $\mathrm{PO}=$ Post-Operation. $\mathrm{n}=6$ for vehicle group, $\mathrm{n}=7$ for melatonin group. Scale bar indicates $100 \mu \mathrm{m}$. 

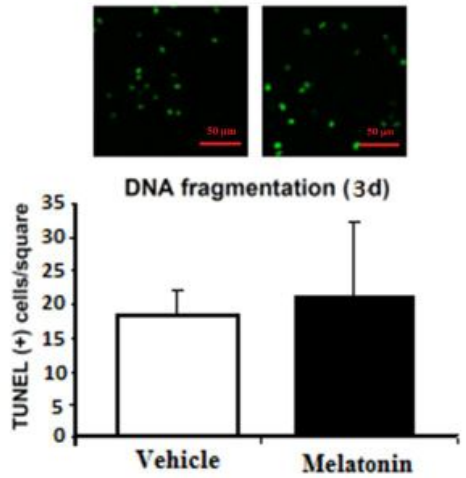

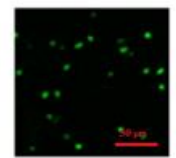

DNA fragmentation (14d)

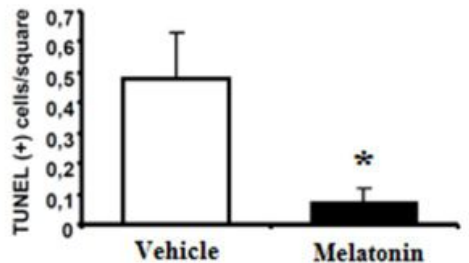

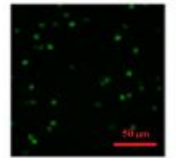

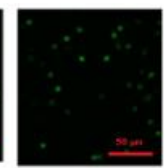

DNA fragmentation (30d)

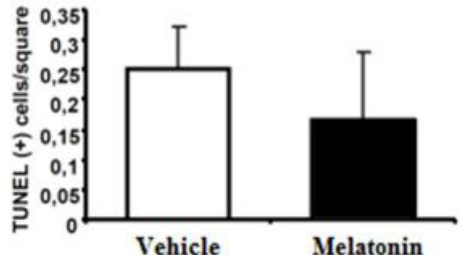

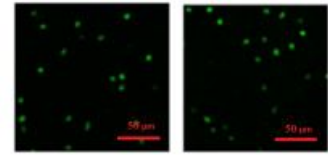

DNA fragmentation (55d)

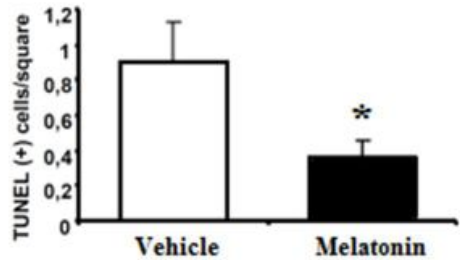

Figure 3

Melatonin decreases disseminated cell death evaluated by terminal transferase biotinylated-dUTP nick end labelling (TUNEL; green fluorescence). Representative microphotographs for TUNEL staining showing DNA-fragmented cells in the striatum are also presented. Data are mean values $\pm S D$. ${ }^{*} p<0.05$ compared with vehicle-treated ischemic mice. $\mathrm{PO}=$ Post-Operation. $\mathrm{n}=6$ for vehicle group, $\mathrm{n}=7$ for melatonin group. Scale bar indicates $50 \mu \mathrm{m}$.
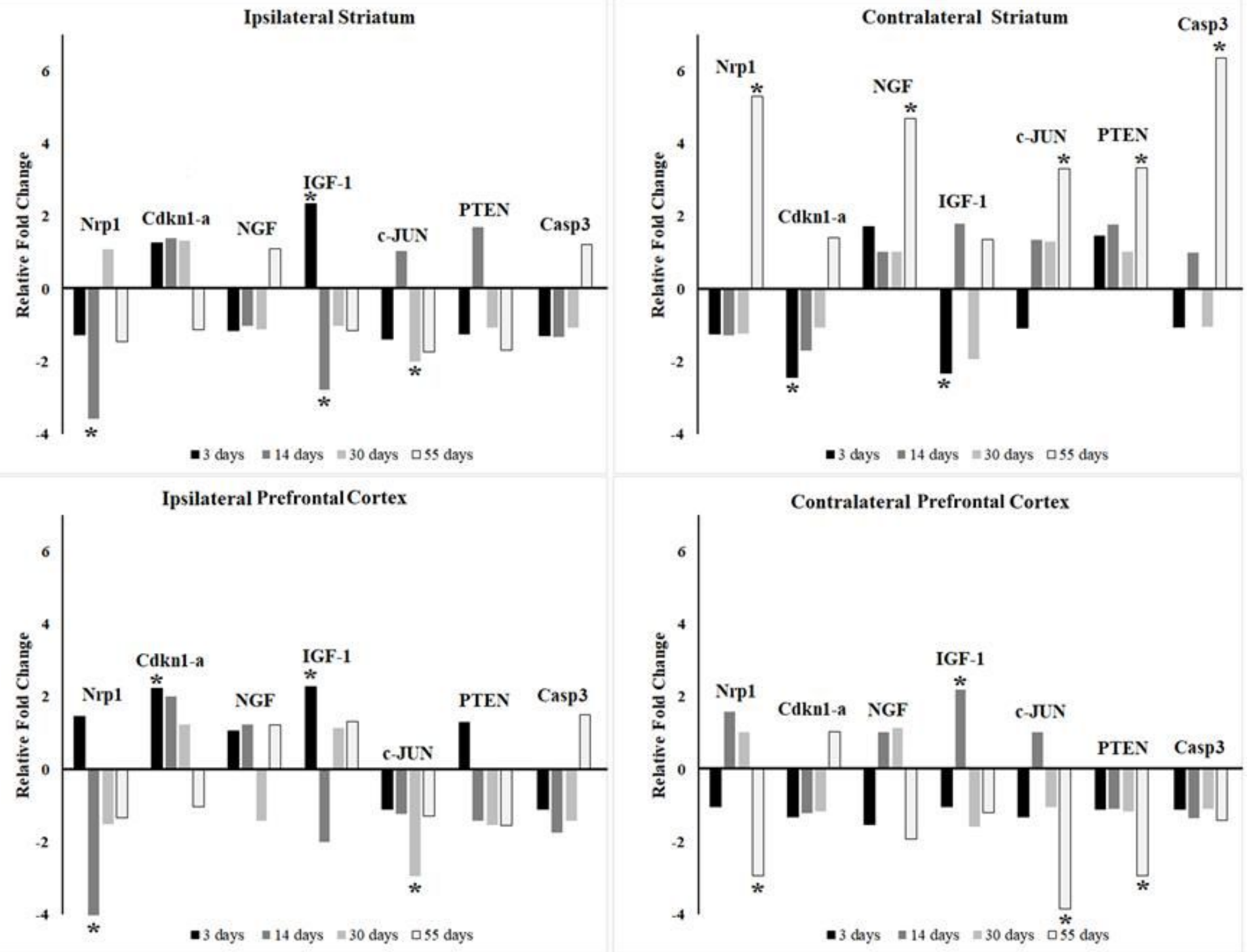
Figure 4

Temporospatial analysis of expression of genes related cell survival and apoptosis in the ipsilateral and contralateral hemisphere by semi-quantitative RT-PCR analysis in the striatum and cortex at days 3,14 , 30 , and 55 post-ischemia. Asterisk (*) shows 2 or more of fold change compared to ischemic control group. $n=6$ for vehicle group, $n=7$ for melatonin group

A
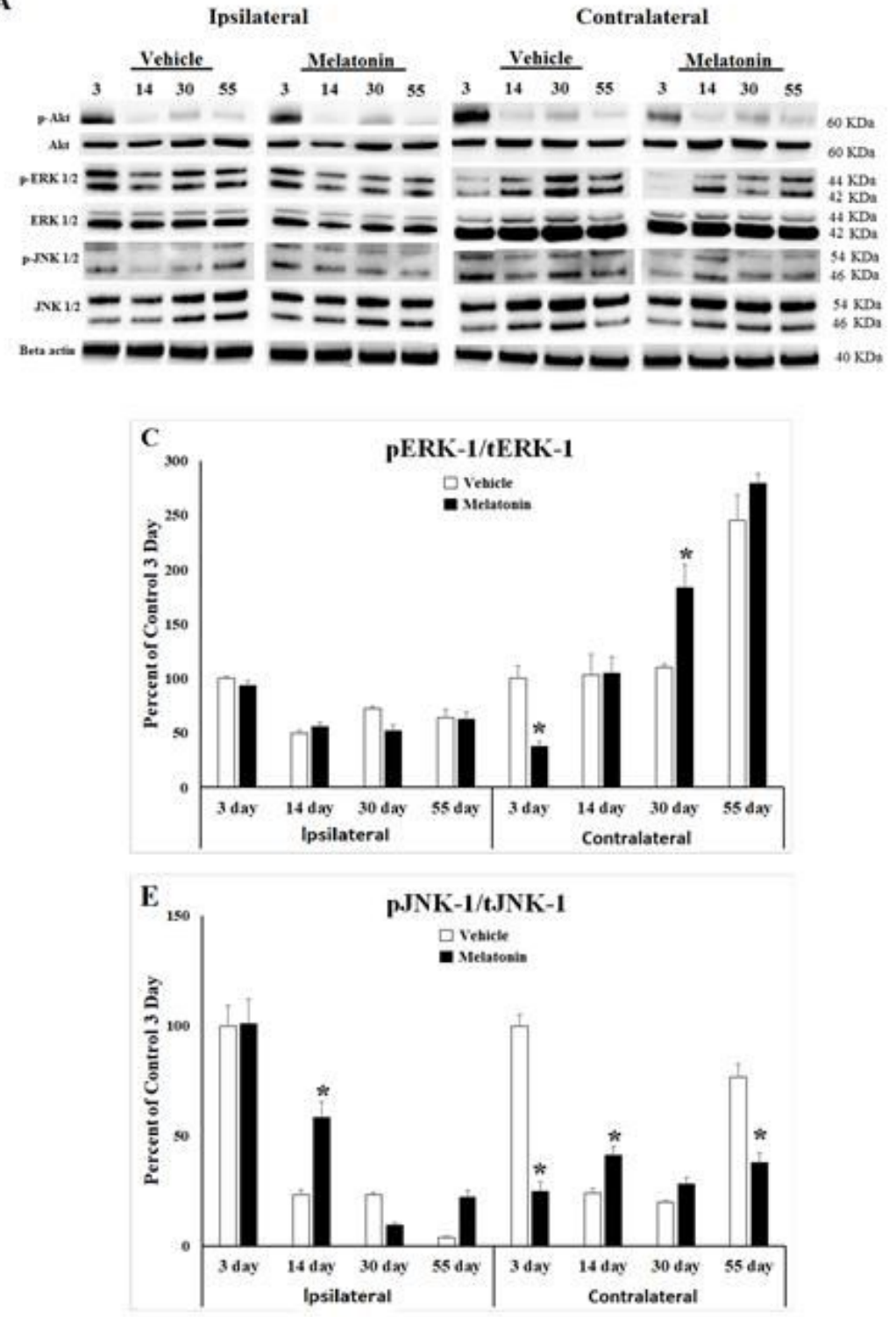

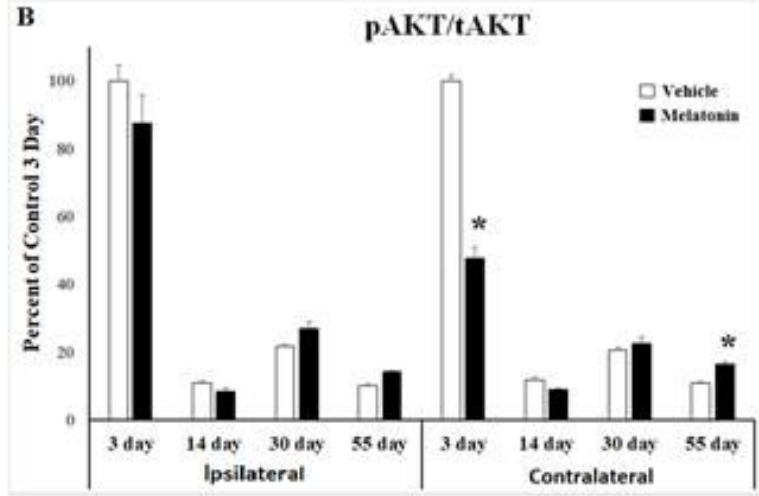

D
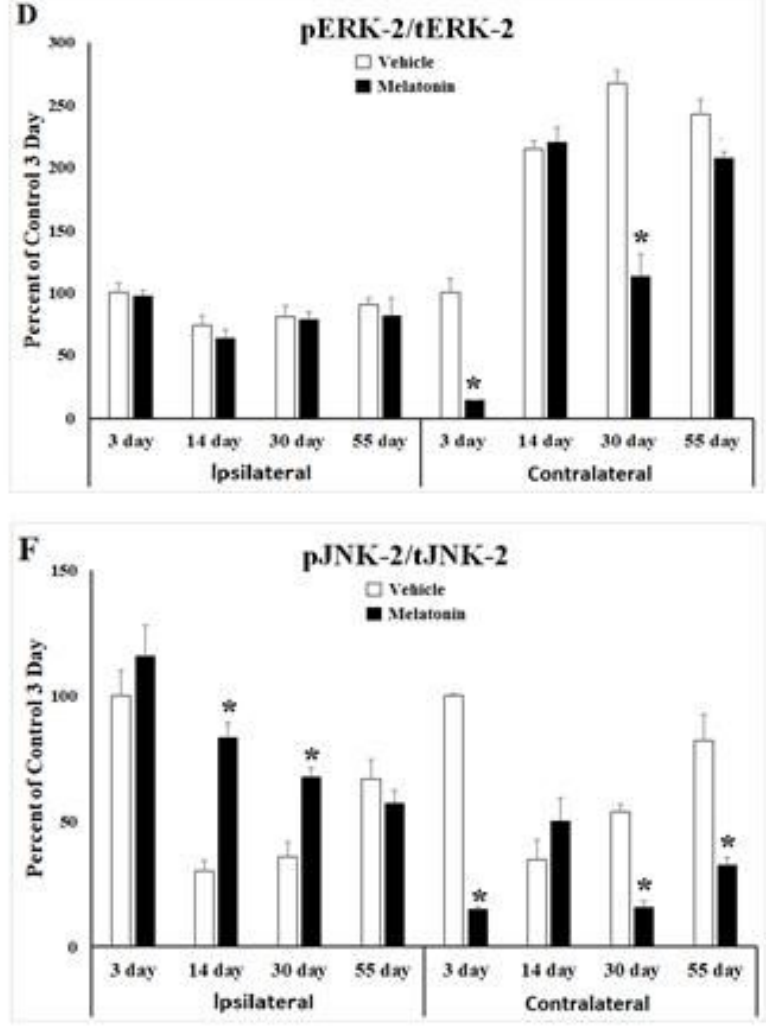

Figure 5

Delayed-melatonin delivery stimulates post-ischemic cell survival and apoptosis Western blots (A) with protein lysates of ipsilateral and contralateral ischemic brains of control and melatonin treated mice to determine the levels of phosphorylated proteins (B) AKT, (C) ERK-1, (D) ERK-2, (E) JNK-1, and (F) JNK-2 at days $3,14,30$, and 55 post-ischemia. Data are mean values $\pm S D$. ${ }^{*} p<0.05$ compared with ischemic vehicle. $\mathrm{n}=6$ for vehicle group, $\mathrm{n}=7$ for melatonin group 
A
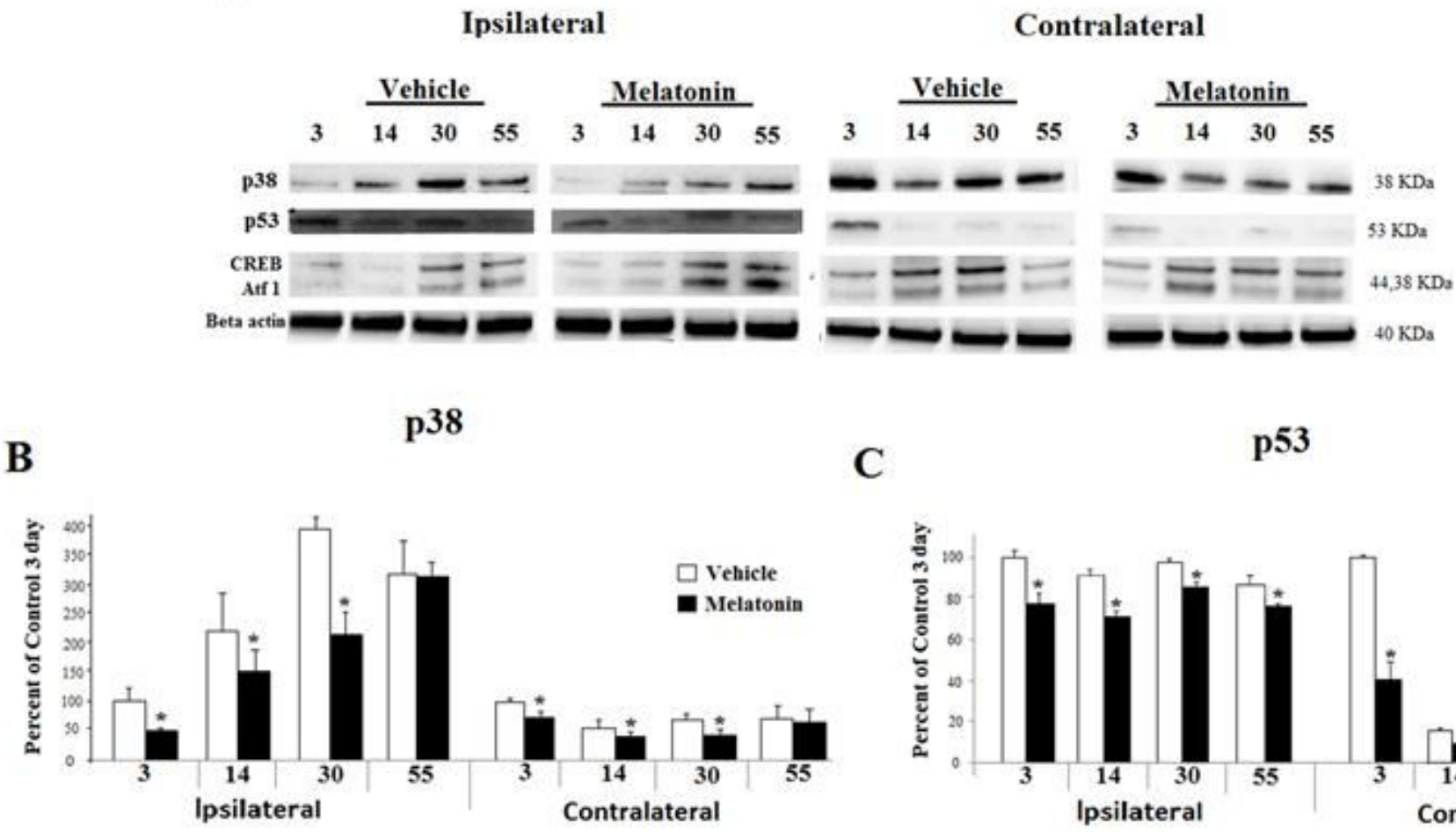

B

D

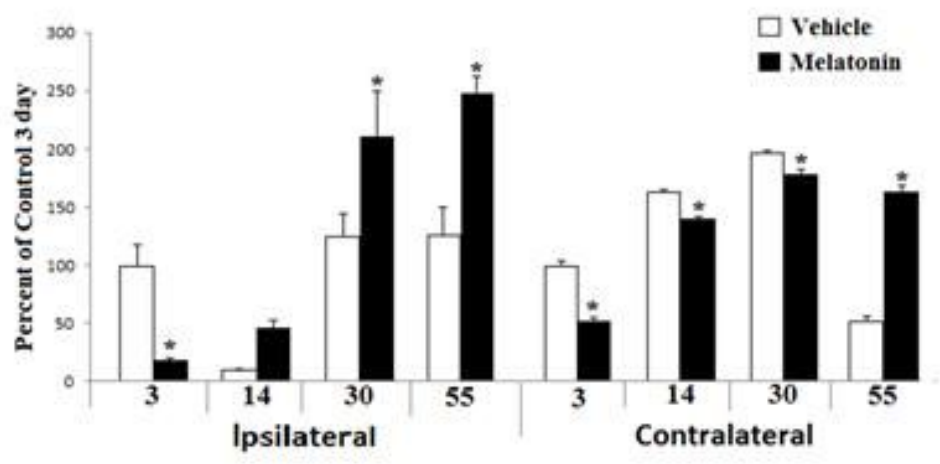

C

p53

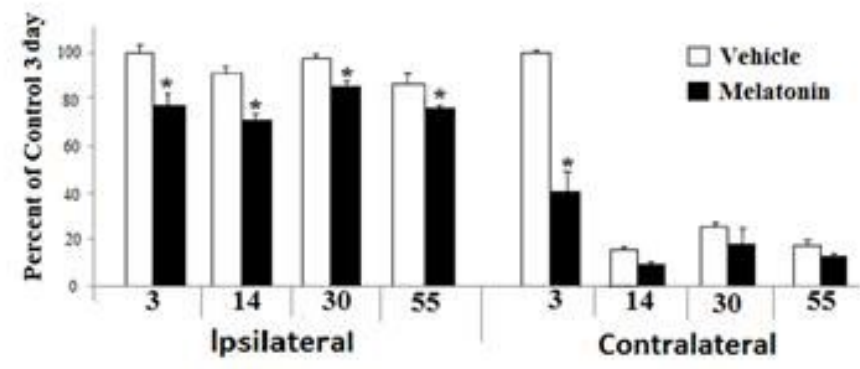

Atf-1

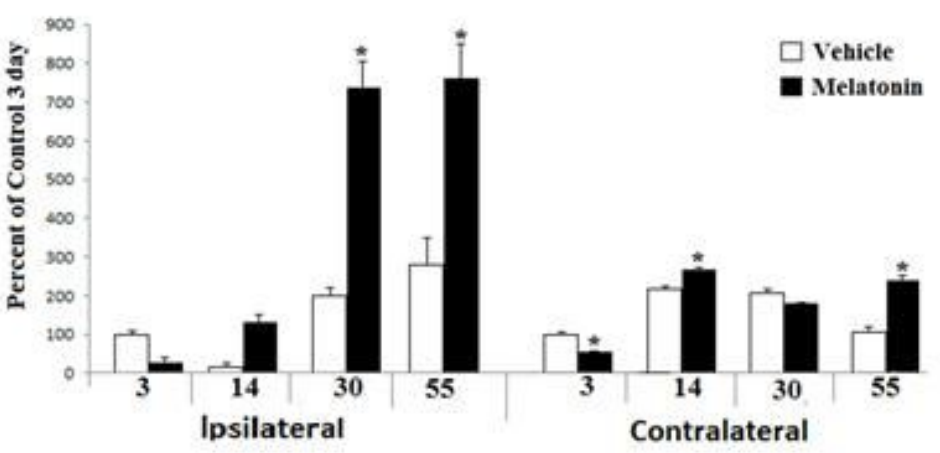

Figure 6

Delayed-melatonin delivery stimulates post-ischemic cell survival and apoptosis Western blots (A) with protein lysates of ipsilateral and contralateral ischemic brains of control and melatonin treated mice to determine the levels of phosphorylated proteins (B) AKT, (C) ERK-1, (D) ERK-2, (E) JNK-1, and (F) JNK-2 at days $3,14,30$, and 55 post-ischemia. Data are mean values \pm SD. ${ }^{*} p<0.05$ compared with ischemic vehicle. $n=6$ for vehicle group, $n=7$ for melatonin group 


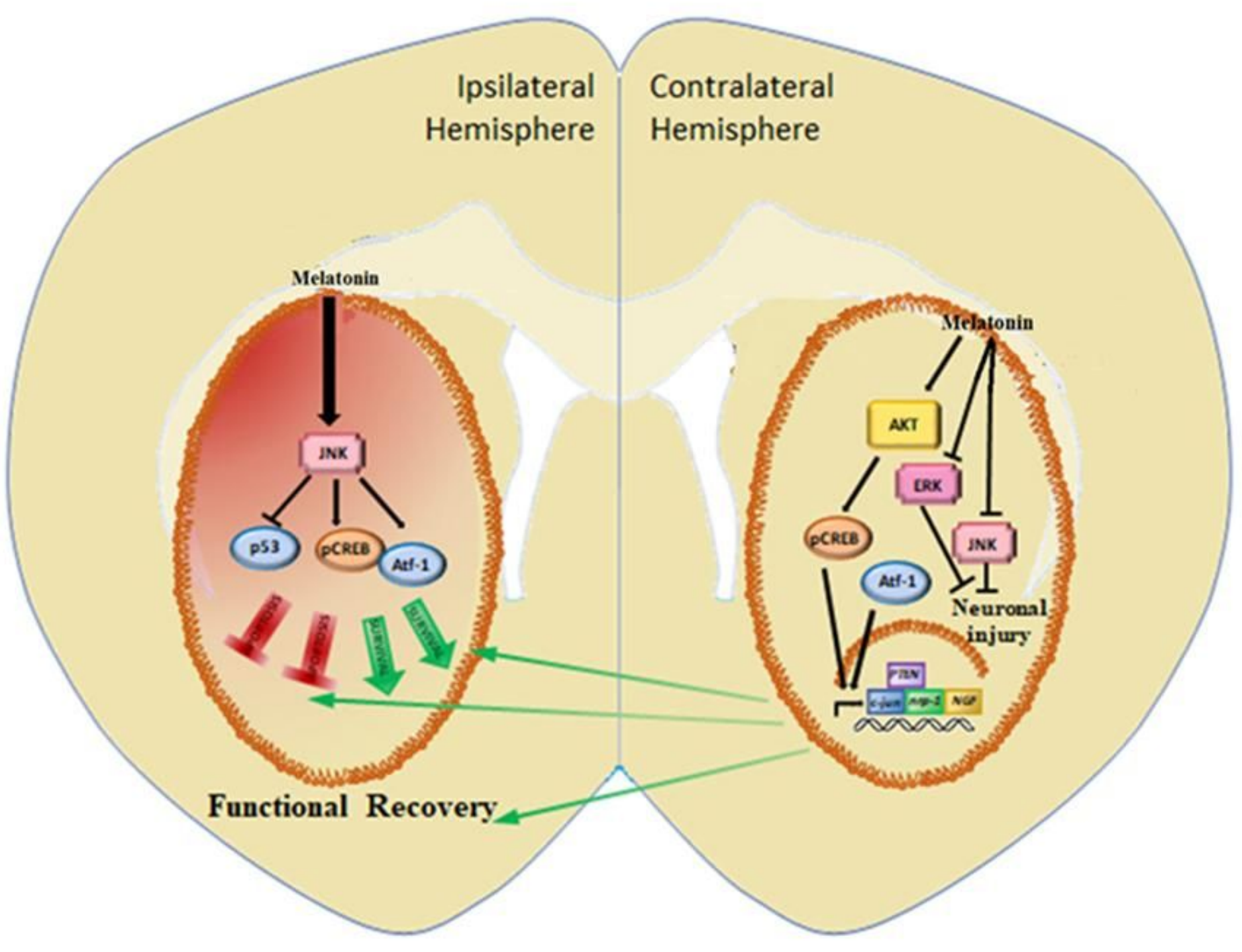

Figure 7

Delayed-melatonin delivery regulates of Akt and MAPK signaling pathways at the 55th day of delayedmelatonin treatments following ischemic-stroke. In the ipsilateral hemisphere, delayed-melatonin administration activates JNK to stimulate CREB and Atf- 1 and inhibit p53 for decreasing apoptosis and increasing cell survival. To support the alterations in the ipsilateral hemisphere, in the contralateral hemisphere, delayed-melatonin administration activates AKT signaling to stimulate CREB-dependent expressions of genes-related cell survival and apoptosis. In addition, in the contralateral hemisphere, melatonin administration inhibits MAPK (ERK and JNK) signaling pathway to protect further neuronal injury.

\section{Supplementary Files}

This is a list of supplementary files associated with this preprint. Click to download.

- graphicalabstract.tif 